\title{
Catheter Balloon Length
}

National Cancer Institute

\section{Source}

National Cancer Institute. Catheter Balloon Length. NCI Thesaurus. Code C150146.

The nominal length of the balloon per manufacturer specification. 